\title{
MANAGING MATURITY IN PROCESS-BASED IMPROVEMENT ORGANIZATIONS: A PERSPECTIVE OF THE ROMANIAN COMPANIES
}

\author{
Carmen Păunescu ${ }^{1}$, Carmen Acatrinei (Pantea) ${ }^{2}$ \\ 1,2 Bucharest University of Economic Studies, 2-2A Calea Griviței street, \\ District 1,010701 Bucharest, Romania \\ E-mails: 1 carmen.paunescu@fabiz.ase.ro (corresponding author); \\ 2 acatrinei.carmen@gmail.com
}

Received 04 February 2011; accepted 11 May 2011

\begin{abstract}
Building upon various models from the literature which assess the maturity level achieved by an organization at one moment in time, the paper introduces a model which helps organizations, interested in remaining competitive and achieving sustainability, to monitor and evaluate their process performance. Such as, the paper analyzes the relationships that exist among the critical components of an organization's management system at the strategic and operational level so that key drivers will become the heart of sustainable development. In particular, the paper focuses on how the organizational system influences process maturity profile of the Romanian companies. Data were collected in face-to-face structured-questionnaire interviews from 1302 public and private organizations from Romania. The dearth of empirical research examining organization process maturity in emerging countries constitutes a critical gap in the business process management literature that needs much more attention from scholars. For the purpose of this paper, a factor analysis was employed to explain the pattern of correlations within a set of observed variables that determine the process maturity profile of the Romanian companies. The research results show that there are strong positive correlations between the variables examined that account for a higher level of maturity and performance of organization's processes.
\end{abstract}

Keywords: organization maturity, process management, maturity assessment, sustainability improvement, factor analysis, Romanian organizations.

Reference to this paper should be made as follows: Păunescu, C.; Acatrinei (Pantea), C. 2012. Managing maturity in process-based improvement organizations: a perspective of the Romanian companies, Journal of Business Economics and Management 13(2): 223-241.

JEL Classification: M10, M11.

\section{Introduction}

Organizations today need performance measures to drive long-term strategies and organizational change, to manage efficiently resources and capabilities and to operate processes effectively and continuously improve (Păunescu 2009a; Bieker 2004). It is no longer enough for companies just to make profits for their stakeholders and to obey 
the law. They are increasingly accountable to more environmentally and socially aware shareholders, to civil society in general, to employees, to customers, to partners and to a variety of other stakeholders (Retief 2007; Bovee et al. 2005). A successful company should have the ability to continuously monitor and assess the external environment for challenges, changes, trends and risks, as well as to analyze its internal environment for opportunities of continuous improvement. It should be able to identify, attract and allocate necessary resources to achieve objectives. Furthermore, to achieve superior business performance, companies should develop a systematic procedure for continuous control performance monitoring and optimization in order for them to determine their overall progress and process results. This is done by combining different control performance metrics and assessment methods, by performing continual assessment of their strategies, functions and operations and by monitoring the maturity level (Jelali 2006; Strandskov 2006; Julien et al. 2004; Eickelmann 2004; Knox et al. 2003; Ravichandran, Rai 2000; Pfleeger 1995). At the same time, the company needs to have the ability to continuously learn, change and innovate to be competitive. The creation and sustainable development of the companies is now central to our economic and social lives (Bieker 2004).

There are a growing number of evaluation models being provided to organizations, either directly or indirectly, to assist with the assessment of how mature an organization is (Fitterer, Rohner 2009; Kent Crawford 2006; Cooke-Davies 2004, to name a few of them). Over the years, maturity models have been used in many industries. At the same time, there is an intense interest inside organizations in the topic of how to best measure process performance and enhance customer relationships (Cater-Steel et al. 2006; Lindgreena et al. 2006). The use of such an assessment tool should enable the company to determine its ability to maintain or develop process performance in the long term, as well as ability to manage the development, acquisition, and maintenance of its products or services. It also helps the company to appraise its organizational maturity or process area capability, establish priorities for improvement, and implement these improvements.

In this context, building upon various models provided in the literature, the paper introduces a maturity model, which was designed to help the Romanian companies to assess the current level of performance and further improve. In the paper we analyze the relationships that exist among the critical components of an organization's management system at the strategic and operational level so that key drivers or outcomes will become the heart of sustainable development. In particular, the paper examines how the organizational system influences process maturity profile of Romanian companies, and the degree to which process maturity level plays a role in sustainability improvement. The paper employs a factor analysis to explain the pattern of correlations within a set of observed variables that determine the process maturity profile of the Romanian companies. However, it is important to provide advanced empirical evidence to substantiate our beliefs.

The remainder of the paper is organized as follows. Next part offers a brief overview of the process maturity concept and the requirements for those organizations that aim 
at being sustainable. The coming section presents our arguments of conceptualizing the major constructs (dimensions) that constitute a sustainability-oriented organizational management system for the organizations. The section suggests a model that establishes theoretical relationships between these dimensions. The subsequent section interprets the results and discusses the findings. The paper ends with a section of conclusions.

\section{Organization process maturity: a review of the literature}

Maturity assessment approaches originate mainly from the field of quality management. The concept of maturity has been first introduced in Crosby's quality management maturity grid (CQMM) (Crosby 1979). Crosby (1979) defined five evolutionary stages of how an organization adopts quality management practices. The concept of process maturity is continually being used in many aspects of organizations as a means of assessment or as a part of a framework for improvement. Maturity means "the extent to which an organization has explicitly and consistently deployed processes that are documented, managed, measured, controlled, and continually improved". (CMMI Product Team 2002: 582). The concept of process maturity derives from the understanding that processes - like products or organizations - have life cycles or clearly defined stages that can be managed, measured, monitored and controlled (Söderberg, Bengtsson 2010; Hermann et al. 2007).

The notion of measuring an organization's maturity has been the subject of various academic papers (April, Abran 2009; Antonucci et al. 2004; Ravichandran, Rai 2000; Harter et al. 2000; Rosenquist 1997; Humphrey 1989; Scott 1974). International standards also provide different models for assessing an organization's maturity level (ISO 9004, ISO/IEC 15504). A maturity model can be used as a benchmark for comparison and as an aid to understanding the business processes. By understanding a maturity model, organizations can use this to help not only assess their current maturity level, but also to help efficiently advance them to a higher level of maturity (Meidani et al. 2010; Veronesi, Visioli 2010; Rad, Levin 2006; Antonucci et al. 2004).

The maturity level of an organization provides a way to predict its future performance within a given discipline or industry. Experience has shown that companies do their best when they focus their process-improvement efforts on a manageable number of process areas or those business decisions that require increasingly sophisticated effort as the organization improves (Ladley 2010; Yuan et al. 2009; Zinkevičiūte 2007; Humphrey 1989). A maturity level is a defined evolutionary scale of process improvement. Each maturity level stabilizes an important part of the organization's processes (CMMI Product Team 2002). Any attempt to skip maturity levels is counterproductive, since each level builds a foundation from which to achieve the next level (Söderberg, Bengtsson 2010).

The companies have adopted various competition strategies to reduce product development time and deliver higher quality products and services to their respective customers at lower costs. Under time-based competition, the companies strive to constantly improve the reliability and capability of their manufacturing processes, but also improve 
the after-sales services (Harter et al. 2000). A key premise underlying process improvement in manufacturing is the elimination of waste and rework in manufacturing activities by reducing product defects. These improvements are thought to arise from reduced defects, scrap and rework in a mature manufacturing process. Harter et al. (2000) found that improvements in process maturity lead to higher quality. However, higher quality in turn leads to reduced cycle time and development effort in the products. Jiang et al. (2004) found that by examining performance of projects in relation to the activities at various levels of maturity, the activities associated with the managerial control of development related positively to project performance measures. Even so, there are many reasons which explain why companies do not adopt a capability maturity model, such as: the size, costs involved, and time required (Staples et al. 2007).

Literature provides different models for assessing an organization's maturity level. A maturity model can be used as a benchmark for comparison of different organizations where there is something in common that can be used as a basis for comparison. In the following paragraphs we address some of the most popular maturity models which proved to be successful when applied by companies.

The ISO 9004:2009 international standard provides organizations with guidelines and tools on the application of the eight quality management principles to the purpose of achieving long term sustainable success. Although, the organizations have at their hand, through this standard, guidance on managing the movement of the organization as a whole, rather than just some of its constituent parts, towards increasing performance. According to ISO 9004, there are five levels of maturity that organizations can attain, namely: (1) "beginner" organization, (2) "proactive" organization, (3) "flexible" organization, (4) "innovative" organization and (5) "sustainable" organization. The maturity levels are derived from the same eight principles of quality management (ISO 9000:2005) and determine the level of maturity of an organization in relation to six criteria: organization's environment; strategies, policies and communication; resources; processes; measurements and analysis, and learning, improvement and innovation. For attaining the levels of "innovative" or "sustainable", an organization must take into account different mechanisms and instruments for results' evaluation, that can be implemented both at strategic and operational level.

A second maturity model, also known as SPICE (Software Process Improvement and Capability dEtermination), makes the purpose of another international standard, ISO/ IEC 15504 (Joint Technical Subcommittee between ISO - International Organization for Standardization and IEC - International Electrotechnical Commission). The standard provides a framework for the assessment of processes, which can be used in two contexts: process improvement, and capability determination, respectively evaluation of supplier's process capability. ISO/IEC 15504 is the reference model for maturity models (consisting of capability levels which in turn consist of process attributes and further consist of generic practices) against which the assessors can place the evidence that they collect during their assessment, so that the assessors can give an overall determination of the organization's capabilities for delivering products. The SPICE criteria levels can 
be applied to an organization in order to determine its level of maturity in relation to people, process, technology, and measurement. The levels 0 to 5 in the model are the following: (0) incomplete, (1) performed, (2) managed, (3) established, (4) predictable, and (5) optimizing.

Another maturity model suggested for our research was firstly described by Watts Humphrey (1989) and is known as Capability Maturity Model (CMM). The CMM is a process capability maturity model which aids in the definition and understanding of an organization's processes. The model was developed by the Software Engineering Institute (SEI) of Carnegie Mellon University for the software engineering process. The CMM is now popular and has been effective in emphasizing the importance of process improvement. Anecdotal evidence suggests that organizations implementing CMM-based software process improvement have incurred gains in the development time cycle and programmer productivity (Xirogiannis, Glykas 2007; Pooley, Wilcox 2004; Ravichandran, Rai 2000). Process-maturity measured on the CMM maturity scale reflects the company's level of investment to improve software process capabilities. The CMM framework includes 18 key process areas such as quality assurance, configuration management, defect prevention, peer review, and training (Ravichandran, Rai 2000). The CMM model identifies five levels of process maturity for an organization, namely: (1) initial (ad hoc, chaotic), (2) repeatable (process discipline), (3) defined (institutionalized), (4) managed (quantified, measured), and (5) optimized (process improvement).

Building upon the CMM model, Niazi et al. (2005) design a maturity model for implementation of software process improvement, which has three dimensions -maturity stage dimension, critical success factor dimension and assessment dimension. It provides a very practical structure with which to assess and improve software implementation processes. A similar model was developed for assessing the maturity of requirements engineering process (Niazi et al. 2007). Rainer and Hall (2002), using a maturity-based analysis, report that the key success factors that impact majorly software process improvement are reviews, standards and procedures, training and mentoring, and experienced staff, internal leadership, inspections, executive support and internal process ownership, that the more mature companies considered.

Andersen and Jessen (2003) propose a model to assess project maturity in organizations along three dimensions: knowledge (capability to carry out different tasks), attitudes (willingness to carry them out), and actions (actually doing them). The different dimensions of maturity are further divided into sub-concepts, which should provide a good understanding of the project maturity of an organization. Demir and Kocabaş (2010) demonstrate how a project management maturity model can enhance the quality of education delivered. Implementation of such model allows the educational organization to identify the steps needed to be taken for accomplishing the expected results and in what sequence to realize meaningful and measurable results. Kent Crawford (2006) introduces a five-level maturity model to assess project management in organizations against the following knowledge areas: integration, scope, time, cost, quality, human resources, communications, risk, and procurement. The five levels, similar to those of 
the CMM model are as follows: (1) initial process, (2) structured process and standards, (3) organizational standards and institutionalized process, (4) managed process and (5) optimizing process.

Other researchers Cooke-Davies and Arzymanow (2003) investigate the nature and extent of variations between project management practices in different industries. They found that the most highly developed project management models were found in the Petrochemical and Defense industries, which on average scored highly on most dimensions considered for assessment. This can be considered to equate a measure of project management maturity in that particular industry.

Lee et al. (2010) introduce a maturity model based on communities of practice evaluation framework which helps Korean companies to move from immature, inconsistent activities to mature, disciplined approaches aligned to strategic business imperatives.

Gottschalk (2008a) proposes a four-stage maturity model for criminal organizations. The maturity levels are activity-based, knowledge-based, strategy-based, and valuebased criminal organizations, respectively. Also, Gottschalk (2008b) introduces a conceptual four-stage maturity model for email communication in knowledge organizations. The stages are labeled person-to-technology, person-to-person, person-to-information and person-to-application, respectively. A similar model was also developed for interoperability in digital government (Gottschalk 2009). The maturity levels are: (1) computer interoperability, (2) process interoperability, (3) knowledge interoperability, (4) value interoperability, (5) goal interoperability. Similarly, Andersen and Henriksen (2006) propose an e-government maturity model by focusing IT applications to improve the core activities and bring end-users as the key stakeholders for future e-government investments.

Another stream of research regards Rosenthal and Vigeland's work (1996) which proposes a maturity benchmarking method to assess process performance for electronics organizations, as an indicator of industry practices, such as: customer requirements gathering, customer involvement in development, training and support of managers and engineers, use of aids for electronic design and component data transfer. Kruger (Neels) and Johnson (2010) demonstrate how information and communications technology and information management enhance knowledge management maturity of organizations.

Berg et al. (2002) present a method for assessing the quality and maturity of R\&D against six viewpoints: business strategy, product and technology strategy, strategic implementation, R\&D as a business section, outputs, and implementation of R\&Dprojects. Procedures in each of the six viewpoints are assessed and scored by five maturity levels.

Strutt et al. (2006) introduce a design safety capability maturity model, outlining the key processes considered necessary to safety achievement. The maturity levels defined and the scoring methods are related to regulatory mechanisms and risk based decision making together with the environmental risk management. 
Other researchers Fitterer and Rohner (2009) propose a networkability maturity model for health care providers. The components of this assessment model are: IT management, process management, organizational project management, cooperation management, and systems architecture. The five maturity levels are defined as follows: initial, managed, defined, quantitatively managed, and optimizing (CMMI Product Team 2002).

Besides the above mentioned assessment models, numerous other performance assessment models exist in the literature with the purpose of helping the companies to advance their business to an upper level of performance. It is worth to mention here the well known models like Total Quality Management (TQM), Six Sigma or Business Process Management, which do not make the object of our direct investigation because of the high complexity of this research and space constraints. Additionally, the paper deals mainly with researching multiple maturity models adopted by companies operating in different fields and industries, with the purpose of designing a generic model for maturity assessment in the Romanian organizations. However, various works were considered to understand the links between the ISO 9000 requirements, TQM model and Six Sigma practices (Yang, Hsieh 2009; Zu et al. 2008) and to investigate the models' impact on innovation and firm performance (Mellat-Parast 2011; Quist et al. 2007).

Therefore, when it comes to choosing an appropriate assessment model for a particular type of business it is important to know that the assessment criteria have a critical role in the success of assessments, but the customers may have different purposes for assessments (Jokela 2004). Such as, for the purpose of this research, we focused mainly on understanding how various maturity assessment models work for different industries and what are the critical dimensions which describe a successful business and drive its competitiveness on the market. Limited attention has been devoted to define process management, identify and define its constitutive dimensions, and develop reliable and valid measurement instruments for each of these dimensions (Ravichandran, Rai 2000). Furthermore, the dearth of empirical research examining organization process maturity in emerging countries constitutes a critical gap in the business process management literature that needs much more attention from scholars. Additionally, none of the maturity models existing in the literature do not link the internal and external results achieved by a company with sustainability improvement. Integrative theory development is required to understand the relationships between process management practices and other elements of the organization management system, which enable or constrain effective process management. Attempts to design a unified model for implementation of a maturity model in organizations exist and are valuable as they resolve various issues related to business process performance (Mellat-Parast 2011; Zu et al. 2010; Yoo et al. 2006).

In this context, for the purpose of this paper, a maturity model was proposed in an attempt to integrate the fundamental features of the most commonly spread maturity assessment models mentioned above, to meet particular needs and characteristics of the Romanian companies. The main goal of such an assessment tool is not only to assist Romanian organizations with the evaluation of their business performance, but to help them to advance the maturity level of each one of their key processes or other processes. 


\section{Conceptual model and research approach}

\subsection{Research model}

The core model introduced in the paper builds, mainly, upon the concept of managing process performance for sustainability improvement developed by the international standard ISO 9004:2009, and tries to integrate all components of an effective organizational management system as they are described by various research models mentioned above. Romanian companies have particular needs concerning the necessary resources, operations and the target market; also, their business performance assessments cannot be described as current practices throughout the organizations. Therefore, a more simplistic, but effective assessment model is required for the Romanian organizations, to help them evolve faster and smarter in a more and more dynamic and competitive world, and achieve sustainable success.

According to the ISO 9004:2009 the sustainability of the organization is reliant on its ability to independently monitor the external environment for opportunities, changes, trends and risks and analyze its internal environment. At the same time, the organization needs to have the ability to learn, change and innovate in response to the results of monitoring, through cohesive, efficient and aligned processes that are based on quality management principles. The sequence of steps needed for the process of managing for sustainability follows the well known "Plan-Do-Check-Act" (or P-D-C-A) cycle, which seems to work properly in our case (considering the particular characteristics of the Romanian organizations and "easy-to-use" feature of this improvement tool).

Drawing from the above business process management literature and focusing mainly on developing an organizational management system for sustainability improvement, we introduce a conceptual framework which integrates ten dimensions that inter-relate each other. Other researches also pointed out the significance of most of these key business factors in the overall business performance of an organization (Ahmed, Capretz 2010; Yang, Hsieh 2009; Zu et al. 2008; Yoo et al. 2006; CMMI Product Team 2002). The ten dimensions of the maturity model proposed are the following: (1) Organizational context; (2) Strategic planning; (3) Risk management; (4) Process management; (5) Human resource management; (6) Results analysis; (7) Performance indicators; (8) Learning; (9) Improvement, and (10) Innovation. To discuss the organization process maturity profile at operational level we developed a model that inter-relates these variables with the organization's maturity level and are specified as drivers of sustainability improvement (see Fig. 1). The model is tested using data collected from 1302 companies from Romania.

The variables to be studied --against which organization process maturity at strategic and operational level can be described and assessed-- are defined as folows: (1) Organization context (OrgContext) assesses the extent to which the organization monitors and analyzes its external and internal environment, and collects ongoing data and information about it; (2) Strategic planning (StrategPlan) assesses the degree to which the organization develops strategic orientations and policies based on the risks and opportunities identified and determines its current and future capabilities needed for sustain- 


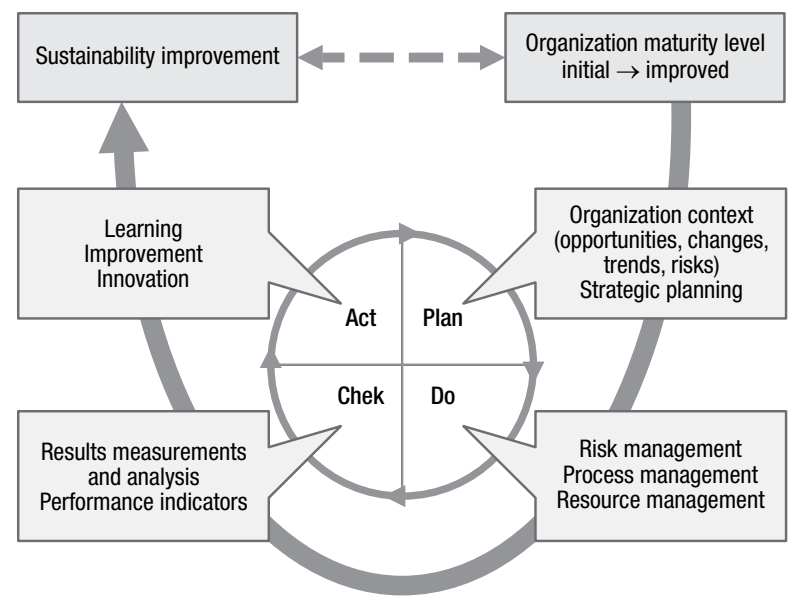

Fig. 1. Conceptual model

ability; (3) Risk management (RiskManag) measures the degree to which the organization identifies and analyses the risks in cost, time, quality, technology, resources, etc.; (4) Process management (ProcessManag) assesses the degree to which the organization uses a 'process approach' to identify its processes and their interactions, and appoints 'process owners' to ensure process responsibility and authority; (5) Resource management (ResManag) measures the extent to which the organization identifies the resources that are critical to its development and achievement of performance, develops a plan for providing, controlling, monitoring, protecting and developing its resources, assesses its resources needs and establishes priorities for the allocation of resources; (6) Results measurement and analysis (ResultEval) assesses the extent to which the organization monitors and measures systematically the performance of all its relevant processes; (7) Performance indicators (Indicators) identifies the organization's key performance indicators, monitors the degree and speed at which it achieves its objectives, and takes corrective action when objectives are not met; (8) Learning (Learning) assesses the extent to which the organization detects changes and trends in its business environment and establishes the culture of a learning organization; (9) Improvement (Improv) measures the extent to which the organization defines objectives for improvement and seeks to achieve these objectives, and (10) Innovation (Innovation) assesses the degree to which the organization innovates in its capabilities and organizational constitution as necessary to ensure future success.

The aim of the paper is to identify the degree to which the Romanian organizations assess process maturity at both strategic and operational level and offer continued satisfaction to their stakeholders, and to help organizations identify areas in which they can improve their performances. As it was mentioned before, the paper examines how the organizational system of the companies participating in the survey influences process maturity profile, and the degree to which process maturity levels play a part in their sustainability improvement. 


\subsection{Sample and data collection}

For the collection of the data, respondents were asked to fill in a statistical research instrument - namely Maturity Assessment Survey (MAS), which collected information on the strategic and operational maturity level of the organization (Păunescu 2009b). Multiple managers, quality managers and other executives from Romanian organizations filled in the questionnaire in their organizations. The MAS was designed to identify the degree to which organizations are sustainable and offer continuous satisfaction to their stakeholders, and to help organizations identify areas in which they can improve their performances. The questionnaire behind the model was designed to answer how the companies work with their processes, how they define and document them, and how they measure and link them vertically and horizontally. The questions can apply to small companies (SMEs) as well as large organizations (public and private).

The sample consisted of 1302 Romanian organizations that met the following sampling criteria: (1) respondents have been working with the company as quality manager/ responsible or other executive position for more than six months, (2) company has been in operation at least three years, and (3) company has at least five employees. The reporting companies represented a range of industries, including commerce and sales $(46 \%)$, real estate $(15 \%)$, consulting $(10 \%)$, distribution and transportation $(7 \%)$, banking and insurance $(6 \%)$, IT $(6 \%)$, telecommunications $(3 \%)$, advertising $(2 \%)$, and a mix of other industries (5\%). The companies had been present on the market for a significant number of years (average $=8.5$ ). As regards the organization size, $26 \%$ of companies have less than 10 employees $(n=339), 34 \%$ of them employ between 10 and 49 employees $(n=443), 23 \%$ of organizations employ between 50 and 249 employees $(n=299)$, and $17 \%$ of organizations employ more than 250 employees $(n=221)$. Of the 1302 responding organizations, $820(63 \%)$ achieved profitability in the last three consecutive years of operation or more. The sample consisted of 664 men $(51 \%)$ and 638 women $(49 \%)$, while $31 \%$ were general managers $(n=404), 22 \%$ quality managers $(n=286)$ and $47 \%$ were from various executive positions $(n=612$ : sales and marketing managers, financial managers, operations managers, HR managers, product managers, account managers, etc.). The average age of respondents was 38 years. Data were collected by students and graduates who completed quality management courses at the Faculty of Business Administration from the Bucharest University of Economic Studies. The responses were gathered during October 2007 and January 2009, through face-to-face interviews (100\%), using a structured questionnaire. Out of more than 1500 Romanian organizations which were asked to participate in the study, 1420 agreed to fill in the survey for a $90 \%$ of response rate.

Through interviews we could ensure that all data needed were in place. With interviewing we could be sure that the respondents understood the questions, so the data based on wrong assumptions could be kept to a minimum. Our approach also allowed us to explain the unclear concepts, making them easier for the respondents to understand the criteria for evaluating the company's maturity.

All this being said, it must be underlined that the respondents were not selected at random and therefore generalization is an important limitation of the study. Nevertheless, the present paper could prove a solid basis for further research in the fields it addresses. 


\subsection{Factor analysis}

Factor analysis is used to identify underlying variables, or factors, that explain the pattern of correlations within a set of observed variables. The method of factor extraction used in this paper is Principal components.

We took into account the ten categories of variables described above, for which factor analysis was employed to explain the pattern of correlations within variables that determine the process maturity profile of the Romanian companies. The descriptive statistics for this group of variables is presented in Table 1. The Cronbach's Alpha score for these variables was 0.945 , over 0.7 , which highly meets the reliability requirements of the analysis.

Table 1. Descriptive statistics

\begin{tabular}{lccccc}
\hline & $\mathrm{N}$ & Minimum & Maximum & Mean & Std. Deviation \\
\hline OrgContext & 1302 & 1.00 & 5.00 & 4.1013 & 0.64390 \\
\hline StrategPlan & 1302 & 0.73 & 7.87 & 4.3126 & 0.64241 \\
\hline RiskManag & 1302 & 0.00 & 5.00 & 3.8709 & 0.83338 \\
\hline ProcessManag & 1302 & 0.64 & 5.21 & 3.8948 & 0.68336 \\
\hline ResManag & 1302 & 0.82 & 5.24 & 3.9018 & 0.72492 \\
\hline ResultsEval & 1302 & 0.33 & 5.11 & 4.1834 & 0.70511 \\
\hline Indicators & 1302 & 1.04 & 5.08 & 3.8302 & 0.74784 \\
\hline Learning & 1302 & 0.00 & 6.20 & 3.8092 & 0.75764 \\
\hline Improv & 1302 & 0.00 & 5.00 & 4.1336 & 0.81643 \\
\hline Innovation & 1302 & 0.00 & 5.00 & 4.0033 & 0.76178 \\
\hline Valid N (listwise) & 1302 & & & & \\
\hline
\end{tabular}

We observe that the greatest scores in our sample were obtained by Strategic planning and deployment and Results analysis, while the smallest scores were obtained by Performance indicators and Learning. This may suggest that the use of a systematic process approach to manage process performance and interactions between them, as well as the development of inter-relating strategic and operational processes are key drivers for achieving performance and sustainability improvement. Table 2 shows that any of the ten items is relevant for analysis and increases its reliability. Nevertheless, the deletion of any of the ten items would lead to a decrease in reliability, which means that keeping them all is desirable.

We notice that all items are significantly correlated with the scale. The weakest correlation with the rest of the scale is for the ninth item, Improvement, while the most consistent (the strongest correlation) with the rest of the scale is item seven, Performance Indicators, followed by item eight, Learning and item one, Organization context. The results of the correlation analysis performed on the sample are presented in the following section. 
Table 2. Item-total statistics

\begin{tabular}{lcccc}
\hline & $\begin{array}{c}\text { Scale Mean if } \\
\text { Item Deleted }\end{array}$ & $\begin{array}{c}\text { Scale Variance if } \\
\text { Item Deleted }\end{array}$ & $\begin{array}{c}\text { Corrected Item- } \\
\text { Total Correlation }\end{array}$ & $\begin{array}{c}\text { Cronbach's Alpha } \\
\text { if Item Deleted }\end{array}$ \\
\hline OrgContext & 35.939 & 29.937 & 0.800 & 0.938 \\
\hline StrategPlan & 35.728 & 30.120 & 0.774 & 0.939 \\
\hline RiskManag & 36.170 & 28.511 & 0.762 & 0.940 \\
\hline ProcessManag & 36.146 & 29.910 & 0.751 & 0.940 \\
\hline ResManag & 36.139 & 29.259 & 0.791 & 0.938 \\
\hline ResultsEval & 35.857 & 29.784 & 0.742 & 0.940 \\
\hline Indicators & 36.210 & 28.901 & 0.812 & 0.937 \\
\hline Learning & 36.231 & 28.844 & 0.808 & 0.937 \\
\hline Improv & 35.907 & 29.106 & 0.706 & 0.942 \\
\hline Innovation & 36.037 & 28.945 & 0.789 & 0.938 \\
\hline
\end{tabular}

\section{Factor analysis results and findings}

The main outputs obtained by employing a factor analysis are presented below.

The first output, the correlation matrix, helps identifying the patterns of relationships between the variables examined.

The Pearson correlation analysis (see Table 3) revealed that there are strong positive relationships between the variables examined, which proves that each one accounts for advancing the maturity level of organization's processes and its sustainability development.

Thus, there is a strong positive correlation between Innovation and Learning (0.787), and a great consistency with Performance indicators (0.72). Also, there is a significant positive correlation between Performance indicators and Learning (0.773). This may suggest that identifying key performance indicators for the organization's relevant processes, monitoring and measuring systematically the performance of its processes, and taking corrective actions when objectives are not met, together with building a continuously improvement and learning environment, are key factors for driving organization development and achieving a higher level of process maturity (and performance). The planned outcomes are monitored and measured and the measures developed provide useful and efficient information concerning the working of the core activities. Furthermore, there is a strong positive correlation between Process management and Results' measurement and analysis. Therefore, cross-functional coordination among business departments, use of a systematic process view of the organization and appointment of process owners responsible for monitoring the processes and their improvement, together with allocation of necessary resources to achieve objectives, shape the consistency of business performance and results.

The Pearson correlation analysis revealed also a lower positive connection between Risk management and Improvement (0.522). Also, there are low correlations between Re- 
Table 3. Inter-item correlation matrix

\begin{tabular}{|c|c|c|c|c|c|c|c|c|c|c|}
\hline & 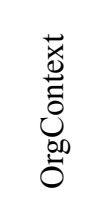 & 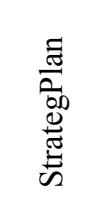 & 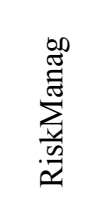 & 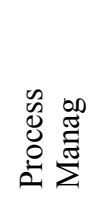 & 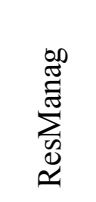 & 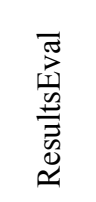 & 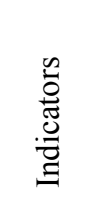 & 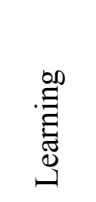 & 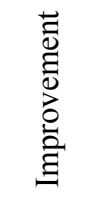 & $\begin{array}{l}\text {.0 } \\
\stackrel{0}{\pi} \\
0 \\
0 \\
\Xi\end{array}$ \\
\hline OrgContext & 1.000 & 0.714 & 0.696 & 0.637 & 0.675 & 0.684 & 0.666 & 0.641 & 0.569 & 0.636 \\
\hline StrategPlan & 0.714 & 1.000 & 0.649 & 0.627 & 0.614 & 0.647 & 0.620 & 0.648 & 0.567 & 0.659 \\
\hline RiskManag & 0.696 & 0.649 & 1.000 & 0.595 & 0.666 & 0.630 & 0.685 & 0.623 & 0.522 & 0.607 \\
\hline ProcessManag & 0.637 & 0.627 & 0.595 & 1.000 & 0.605 & 0.694 & 0.633 & 0.626 & 0.559 & 0.613 \\
\hline ResManag & 0.675 & 0.614 & 0.666 & 0.605 & 1.000 & 0.640 & 0.681 & 0.670 & 0.671 & 0.614 \\
\hline ResultsEval & 0.684 & 0.647 & 0.630 & 0.694 & 0.640 & 1.000 & 0.593 & 0.554 & 0.536 & 0.564 \\
\hline Indicators & 0.666 & 0.620 & 0.685 & 0.633 & 0.681 & 0.593 & 1.000 & 0.773 & 0.600 & 0.720 \\
\hline Learning & 0.641 & 0.648 & 0.623 & 0.626 & 0.670 & 0.554 & 0.773 & 1.000 & 0.623 & 0.787 \\
\hline Improv & 0.569 & 0.567 & 0.522 & 0.559 & 0.671 & 0.536 & 0.600 & 0.623 & 1.000 & 0.623 \\
\hline Innovation & 0.636 & 0.659 & 0.607 & 0.613 & 0.614 & 0.564 & 0.720 & 0.787 & 0.623 & 1.000 \\
\hline
\end{tabular}

Notes: $\mathrm{N}=1302$; Correlation is significant at the 0.01 level (2-tailed)

sults evaluation and Improvement (0.536) and Learning (0.554) and Innovation (0.564). Consequently, the analysis of the core activities contribute to the sustainability of the organization, regardless the identification of the improvement and learning needs about processes, products, structures and systems or determination of the innovations and necessary changes needed to achieve the organization's articulated mission, vision and objectives. Low correlations are also found between Process management and Improvement (0.559), meaning that it could be sufficient for organizations to set up a strategic aim for its core activities that reflects the needs of all its stakeholders in a sustainable way, and define appropriately processes to address the aim for the core activities being considered.

Communalities, the second output, indicate the amount of variance in each variable that is accounted for, before and after extraction. Initial communalities are estimates of the variance in each variable accounted for by all components or factors. Extraction communalities are estimates of the variance in each variable accounted for by the factors (or components) in the factor solution. Principal component analysis works on the initial assumption that all variance is common; therefore, before extraction the communalities are all 1. The communalities in the column labeled Extraction reflect the common variance in the data structure. So, for example we can say that $71.3 \%$ of the variance associated with component 1 - Organization context - is common, or shared, variance. Another way to look at these communalities is in terms of the proportion of variance explained by the underlying factors. Small values indicate variables that do not fit well with the factor solution, and should possibly be dropped from the analysis (see Table 4). In our study such variables refer to Improvement. 
Table 4. Communalities

\begin{tabular}{lll}
\hline & Initial & Extraction \\
\hline OrgContext & 1.000 & 0.713 \\
\hline StrategyPlanning & 1.000 & 0.676 \\
\hline RiskManag & 1.000 & 0.662 \\
\hline ProcessManag & 1.000 & 0.643 \\
\hline HRManag & 1.000 & 0.694 \\
\hline ResultsAnalysis & 1.000 & 0.632 \\
\hline Indicators & 1.000 & 0.726 \\
\hline Learning & 1.000 & 0.720 \\
\hline Improv & 1.000 & 0.578 \\
\hline Innovation & 1.000 & 0.694 \\
\hline
\end{tabular}

Extraction Method: Principal Component Analysis

In Table 5 we have packaged that common variance into two factors, both before and after a varimax rotation:

Table 5. Total variance explained

\begin{tabular}{ccccccc}
\hline Component & \multicolumn{3}{c}{ Initial Eigenvalues } & \multicolumn{2}{c}{ Extraction Sums of Squared Loadings } \\
\cline { 2 - 6 } & Total & $\begin{array}{c}\text { \% of } \\
\text { Variance }\end{array}$ & Cumulative \% & Total & $\begin{array}{c}\text { \% of } \\
\text { Variance }\end{array}$ & $\begin{array}{c}\text { Cumulative } \\
\%\end{array}$ \\
\hline 1 & 6.737 & 67.373 & 67.373 & 6.737 & 67.373 & 67.373 \\
\hline 2 & 0.651 & 6.507 & 73.880 & & & \\
\hline 3 & 0.505 & 5.049 & 78.929 & & \\
\hline 4 & 0.453 & 4.529 & 83.458 & & \\
\hline 5 & 0.399 & 3.992 & 87.450 & & \\
\hline 6 & 0.292 & 2.921 & 90.371 & & \\
\hline 7 & 0.272 & 2.723 & 93.094 & & \\
\hline 8 & 0.265 & 2.646 & 95.740 & & \\
\hline 9 & 0.237 & 2.372 & 98.112 & & \\
\hline 10 & 0.189 & 1.888 & 100.000 & & \\
\hline
\end{tabular}

Extraction Method: Principal Component Analysis

The eigenvalues associated with each linear component (variable) represent the variance explained by that particular factor and SPSS also displays the eigenvalues in terms of the percentage of variance explained (so, factor 1 explains $67.373 \%$ of total variance). It is clear that the first factor - Organization context - explains a relatively large amount of variance whereas the subsequent factors explain only a small amount of variance. 


\section{Conclusions}

This study is one of the first in the Romanian context with such a large pool of respondents. It contributes to understanding maturity of the organization's management system. Various researches were integrated to identify the critical dimensions of an organization management system that shape its process maturity profile and drive its sustainable development in the long term. These dimensions were synthesized into higher level constructs that together define an organizational system. The ten constructs are: organizational context; strategic planning; risk management; process management; human resource management; results analysis; performance indicators; learning; improvement, and innovation. None of the maturity models existing in the literature do not link the internal and external results achieved by a company with sustainability improvement. The model introduced in this paper integrates components, which need to be monitored in the external environment, with components from the internal environment, and are set as key drivers for sustainability development.

The research results show that there are strong positive correlations between the dimensions examined that account for a higher level of maturity and performance of organization's processes. This means that if organizations use the maturity dimensions referred to in this paper, they will most likely achieve a positive effect on their overall performance.

The results of the factor analysis revealed that all variables observed and analyzed account for building process maturity of Romanian companies and increasing their maturity level, and play a role in sustainability improvement in these organizations. This is consistent with the results obtained by Söderberg and Bengtsson (2010), which show that there is a positive and strong correlation between supply chain management maturity in SMEs and quality variables such as delivery performance and productivity, which includes order fulfillment capacity and information system support. This is also consistent with Ravichandran and Rai's (2000) findings, which show that software quality performance is impacted, for example, by process management efficacy, integrated strategy or management infrastructure practices.

The results tell us that the organizations surveyed are more mature in their organizational management system than we expected, with none of the respondents at the lowest maturity level. This could be an indication that even smaller companies or public organizations have begun to fully realize the potential of business process management for performance improvement.

Such as, the Romanian organizations surveyed report that they are aware of and understand their core competences and competitive priorities on the market, consider the needs and interests of various stakeholders of their business offerings, are improvement-oriented, plan to insure predictability of the results, focus on innovation and invest in their capabilities as necessary to ensure future success.

In terms of managerial implications of our study, one implication is that it is effective for a company to focus on its own processes, define and document them, set up process goals, monitor and measure them, and manage them for higher maturity. Furthermore, 
understanding continuous improvements is vital to making companies advance to a higher maturity level.

It must be underlined that the respondents (organizations) were not selected at random and therefore, generalization is an important limitation of the study. Furthermore, due to the large differences in the size of the samples and to the complexity of the questionnaire, the error estimated for data collection and processing is of maximum $5 \%$. Nevertheless, the present paper could prove a solid basis for further research in the fields it addresses. Further empirical evidence to substantiate our research findings is required.

\section{Acknowledgements}

The contribution was prepared under the support of the UEFISCDI-CNCSIS PN II research project, code ID_828/2007, run by the Bucharest University of Economic Studies in Romania. We are grateful for the financial support received.

\section{References}

Ahmed, F.; Capretz, L. F. 2010. A business maturity model of software product line engineering, Information Systems Frontiers: 543-560.

Andersen, E. S.; Jessen, S. A. 2003. Project maturity in organizations, International Journal of Project Management 21(6): 457-461. http://dx.doi.org/10.1016/S0263-7863(02)00088-1

Andersen, K. V.; Henriksen, H. Z. 2006. E-Government maturity models: extension of the Layne and Lee model, Government Information Quarterly 23(2): 236-248.

http://dx.doi.org/10.1016/j.giq.2005.11.008

Antonucci, Y. L.; Corbitt, G.; Stewart, G.; Harris, A. L. 2004. Enterprise systems education: where are we? Where are we going?, Journal of Information Systems Education 15(3): 227-234.

April, A.; Abran, A. 2009. A software maintenance maturity model (S3M): measurement practices at maturity levels 3 and 4, Electronic Notes in Theoretical Computer Science 233(27): 73-87. http://dx.doi.org/10.1016/j.entcs.2009.02.062

Berg, P.; Leinonen, M.; Leivo, V.; Pihlajamaa, J. 2002. Assessment of quality and maturity level of R\&D, International Journal of Production Economics 78(1): 29-35.

http://dx.doi.org/10.1016/S0925-5273(00)00166-3

Bieker, T. 2004. Sustainability Management with the Balanced Scorecard. International Summer Academy on Technology Studies - Corporate Sustainability, Institute for Economy and the Environment at the University of St. Gallen, Switzerland.

Bovee, C. L.; Thill, J. V.; Mescon, M. H. 2005. Excellence in Business. Revised edition. New Jersey: Prentice Hall.

Cater-Steel, A.; Toleman, M.; Rout, T. 2006. Process improvement for small firms: an evaluation of the RAPID assessment-based method, Information and Software Technology 48(5): 323-334. http://dx.doi.org/10.1016/j.infsof.2005.09.012

CMMI Product Team. 2002. Capability Maturity Model Integration (CMMI) Version 1.1. Pittsburgh, PA: Carnegie Mellon Software Engineering Institute.

Cooke-Davies, T. J. 2004. Project management maturity models, in Morris, P. W. G.; Pinto, J. K. (Eds.). The Wiley Guide to Managing Projects (Chapter 49). New York: John Wiley and Sons.

Cooke-Davies, T. J.; Arzymanow, A. 2003. The maturity of project management in different industries: an investigation into variations between project management models, International Journal of Project Management 21(6): 471-478. http://dx.doi.org/10.1016/S0263-7863(02)00084-4 
Crosby, P. B. 1979. Quality is Free - the Art of Making Quality Certain. New York: McGraw-Hill. Demir, C.; Kocabaş, İ. 2010. Project management maturity model (PMMM) in educational organizations, Procedia - Social and Behavioral Sciences 9: 1641-1645.

Eickelmann, N. 2004. Measuring maturity goes beyond processes, IEEE Software 4: 12-13. http://dx.doi.org/10.1109/MS.2004.21

Fitterer, R.; Rohner, P. 2009. Towards assessing the networkability of health care providers: a maturity model approach, Information Systems and E-Business Management 8(3): 309-333. http://dx.doi.org/10.1007/s10257-009-0121-9

Gottschalk, P. 2008a. Maturity model for email communication in knowledge organizations: the case of police investigations, International Journal of Law, Crime and Justice 36(1): 54-66. http://dx.doi.org/10.1016/j.ijs1.2007.07.002

Gottschalk, P. 2008b. Maturity levels for criminal organizations, International Journal of Law, Crime and Justice 36(2): 106-114. http://dx.doi.org/10.1016/j.ijlcj.2007.12.002

Gottschalk, P. 2009. Maturity levels for interoperability in digital government, Government Information Quarterly 26(1): 75-81. http://dx.doi.org/10.1016/j.giq.2008.03.003

Harter, D. E.; Krishnan, M. S.; Slaughter, S. A. 2000. Effects of process maturity on quality, cycle time, and effort in software product development, Management Science 46(4): 451-466. http://dx.doi.org/10.1287/mnsc.46.4.451.12056

Hermann, B. G.; Kroeze, C.; Jawjit, W. 2007. Assessing environmental performance by combining life cycle assessment, multi-criteria analysis and environmental performance indicators, Journal of Cleaner Production 15(18): 1787-1796. http://dx.doi.org/10.1016/j.jclepro.2006.04.004

Humphrey, W. 1989. Managing the Software Process. Boston: Addison Wesley Professional.

Jelali, M. 2006. An overview of control performance assessment technology and industrial applications, Control Engineering Practice 14(5): 441-466.

http://dx.doi.org/10.1016/j.conengprac.2005.11.005

Jiang, J. J.; Klein, G.; Hwang, H. G.; Huang, J.; Hung, S. Y. 2004. An exploration of the relationship between software development process maturity and project performance, Information and Management 41(3): 279-288. http://dx.doi.org/10.1016/S0378-7206(03)00052-1

Jokela, T. 2004. Evaluating the user-centredness of development organisations: conclusions and implications from empirical usability capability maturity assessments, Interacting with Computers 16(6): 1095-1132. http://dx.doi.org/10.1016/j.intcom.2004.07.006

Julien, R. H.; Foley, M. W.; Cluett, W. R. 2004. Performance assessment using a model predictive control benchmark, Journal of Process Control 14(4): 441-456.

http://dx.doi.org/10.1016/j.jprocont.2003.09.002

Kent Crawford, J. 2006. The project management maturity model, Information Systems Management 23(4): 50-58. http://dx.doi.org/10.1201/1078.10580530/46352.23.4.20060901/95113.7

Knox, S.; Maklan, S.; Payne, A.; Peppard, J.; Ryals, L. 2003. Performance assessment process. Customer Relationship Management: 237-256.

Kruger (Neels), C. J.; Johnson, R. D. 2010. Information management as an enabler of knowledge management maturity: a South African perspective, International Journal of Information Management 30(1): 57-67. http://dx.doi.org/10.1016/j.ijinfomgt.2009.06.007

Ladley, J. 2010. Information management maturity, Making EIM Enterprise Information Management Work for Business: 27-35.

Lee, J.; Suh, E.; Hong, J. 2010. A maturity model based CoP evaluation framework: a case study of strategic CoPs in a Korean company, Expert Systems with Applications 37(3): 2670-2681. http://dx.doi.org/10.1016/j.eswa.2009.08.011 
Lindgreena, A.; Palmerb, R.; Vanhammec, J.; Wouters, J. 2006. A relationship-management assessment tool: questioning, identifying, and prioritizing critical aspects of customer relationships, Industrial Marketing Management 35(1): 57-71.

Meidani, Z.; Sadoughi, F.; Maleki, M. R.; Tofighi, S.; Barati Marani, A. 2010. Organization’s quality maturity as a vehicle for EHR success, Journal of Medical Systems.

Mellat-Parast, M. 2011. The effect of Six Sigma projects on innovation and firm performance, International Journal of Project Management 29(1): 45-55.

http://dx.doi.org/10.1016/j.ijproman.2010.01.006

Niazi, M.; Cox, K.; Verner, J. 2007. A measurement framework for assessing the maturity of requirements engineering process, Software Quality Journal 16(2): 213-235.

http://dx.doi.org/10.1007/s11219-007-9033-4

Niazi, M.; Wilson, D.; Zowghi, D. 2005. A maturity model for the implementation of software process improvement: an empirical study, Journal of Systems and Software 74(2): 155-172. http://dx.doi.org/10.1016/j.jss.2003.10.017

Păunescu, C. 2009a. Business Maturity Assessment Model: A Practical Approach for Identifying Opportunities for Sustainability Improvement, in Annals of DAAAM for 2009 \& Proceedings of the $20^{\text {th }}$ International DAAAM Symposium. Katalinic, B. (Ed.). Published by DAAAM International, Vienna, Austria 2009, 0753-0755.

Păunescu, C. 2009b. Managing process performance and quality for sustainability in the service organizations, The Amfiteatru Economic Journal 11(26): 323-329.

Pfleeger, S. L. 1995. Maturity, models, and goals: how to build a metrics plan, Journal of Systems and Software 31(2): 143-155. http://dx.doi.org/10.1016/0164-1212(94)00094-4

Pooley, R.; Wilcox, P. 2004. The capability maturity model for software, Applying UML: 151159.

Quist, J.; Skålén, P.; Clegg, S. R. 2007. The power of quality models: the example of the SIQ model for performance excellence, Scandinavian Journal of Management 23(4): 445-462.

Rad, P. F.; Levin, G. 2006. Project management maturity assessment, AACE International Transactions: PM61-PM70.

Rainer, A.; Hall, T. 2002. Key success factors for implementing software process improvement: a maturity-based analysis, Journal of Systems and Software 62(2): 71-84.

http://dx.doi.org/10.1016/S0164-1212(01)00122-4

Ravichandran, T.; Rai, A. 2000. Quality management in systems development: an organizational system perspective, MIS Quarterly 24(3): 381-415. http://dx.doi.org/10.2307/3250967

Retief, F. 2007. A performance evaluation of strategic environmental assessment (SEA) processes within the South African context, Environmental Impact Assessment Review 27(1): 84-100.

http://dx.doi.org/10.2307/3250967

Rosenquist, D. 1997. The Dell experience: from maturity model assessment to strategic planning, Technical Communication 44(4): 401-405. http://dx.doi.org/10.1016/0166-3615(96)00021-8

Rosenthal, C. W.; Vigeland, R. 1996. An update on a maturity benchmarking process for electronic design processes, Computers in Industry 30(1): 5-11.

http://dx.doi.org/10.1016/0166-3615(96)00021-8

Scott, W. G. 1974. Organization theory: a reassessment, The Academy of Management Journal 17(2): 242-254. http://dx.doi.org/10.2307/254978

Söderberg, L.; Bengtsson, L. 2010. Supply chain management maturity and performance in SMEs, Operations Management Research 3(1-2): 90-97.

http://dx.doi.org/10.1007/s12063-010-0030-6 
Staples, M.; Niazi, M.; Jeffery, R.; Abrahams, A.; Byatt, P.; Murphy, R. 2007. An exploratory study of why organizations do not adopt CMMI, Journal of Systems and Software 80(6): 883895. http://dx.doi.org/10.1016/j.jss.2006.09.008.

Strandskov, J. 2006. Sources of competitive advantages and business performance, Journal of Business Economics and Management 7(3): 119-129.

Strutt, J. E.; Sharp, J. V., et al. 2006. Capability maturity models for offshore organisational management, Environment International 32(8): 1094-1105.

http://dx.doi.org/10.1016/j.envint.2006.06.016

Veronesi, M.; Visioli, A. 2010. Performance assessment and retuning of PID controllers for integral processes, Journal of Process Control 20(3): 261-269.

http://dx.doi.org/10.1016/j.jprocont.2009.12.007

Xirogiannis, G.; Glykas, M. 2007. Intelligent modeling of e-business maturity, Expert Systems with Applications 32(2): 687-702. http://dx.doi.org/10.1016/j.eswa.2006.01.042

Yang, T.; Hsieh, C. 2009. Six-Sigma project selection using national quality award criteria and Delphi fuzzy multiple criteria decision-making method, Expert Systems with Applications 36(4): 7594-7603. http://dx.doi.org/10.1016/j.eswa.2008.09.045

Yoo, C.; Yoon, J.; Lee, B.; Lee, C.; Lee, J.; Hyun, S.; Wu, C. 2006. A unified model for the implementation of both ISO 9001:2000 and CMMI by ISO-certified organizations, Journal of Systems and Software 79(7): 954-961. http://dx.doi.org/10.1016/j.jss.2005.06.042

Yuan, Q.; Lennox, B.; McEwan, M. 2009. Analysis of multivariable control performance assessment techniques, Journal of Process Control 19(5): 751-760.

http://dx.doi.org/10.1016/j.jprocont.2008.10.001

Zinkevičiūte, V. 2007. Evaluation of business strategic decisions under changing environment conditions, Journal of Business Economics and Management 8(4): 267-274.

$\mathrm{Zu}$, X.; Fredendall, L. D.; Douglas, T. J. 2008. The evolving theory of quality management: the role of Six Sigma, Journal of Operations Management 26(5): 630-650.

http://dx.doi.org/10.1016/j.jom.2008.02.001

Zu, X.; Robbins, T. L.; Fredendall, L. D. 2010. Mapping the critical links between organizational culture and TQM/ Six Sigma practices, International Journal of Production Economics 123(1): 86-106. http://dx.doi.org/10.1016/j.ijpe.2009.07.009

Carmen PĂUNESCU is a Full Professor at the Faculty of Business Administration from the Bucharest University of Economic Studies (ASE), Romania. Prof. Paunescu holds a Ph.D. in Economics from ASE. Her qualification raise includes: University of Rome "La Sapienza", Italy - 2004; Harvard Business School - EECPCL 2007, USA; IMTA 2008, Bled, Slovenia and EEC 2009, Maastricht, Holland. Her research interests lie in the areas of organization's maturity assessment, organizational entrepreneurial culture, innovation and corporate entrepreneurship, entrepreneurship education, and cross-cultural management.

Carmen ACATRINEI (PANTEA) is an Assistant Professor at the Faculty of Business Administration from the Bucharest University of Economic Studies (ASE), Romania. Her research and teaching interests lie in the areas of customer relationship management, direct marketing, project management, negotiation techniques and other business-related topics. Carmen holds a Ph.D. in Marketing from ASE. Her area of interest for the doctoral research is related to the online marketing tools used for managing customer relationships. 